Check for updates

Cite this: Chem. Sci., 2019, 10, 11086

๑ All publication charges for this article have been paid for by the Royal Society of Chemistry

Received 3rd September 2019 Accepted 13th October 2019

DOI: $10.1039 / c 9 s c 04437 j$

rsc.li/chemical-science

\section{Temperature induced valence phase transition in intermediate-valent $\mathrm{YbPd}_{2} \mathrm{Al}_{3} \uparrow$}

\author{
Frank Stegemann, ${ }^{a}$ Juliane Stahl, ${ }^{\mathrm{b}}$ Manfred Bartsch, ${ }^{\mathrm{c}}$ Helmut Zacharias, ${ }^{\mathrm{c}}$ \\ Dirk Johrendt ${ }^{\mathrm{b}}$ and Oliver Janka (D) *a
}

A temperature induced valence phase transition from $\mathrm{Yb}^{3+}$ at higher temperatures to $\mathrm{Yb}^{2+}$ at lower temperatures was observed at $T=110(1) \mathrm{K}$ for intermetallic $\mathrm{YbPd}_{2} \mathrm{Al}_{3}$. The title compound has been prepared from the elements in sealed tantalum ampoules. The structure was refined from single-crystal data and the title compound was found to crystallize in the hexagonal $\mathrm{YNi}_{2} \mathrm{Al}_{3}$ type structure with space group $P 6 / \mathrm{mmm}$ and lattice parameters of $a=929.56(7)$ and $c=420.16(3) \mathrm{pm}$ (300 $\mathrm{K}$ data). Full ordering of the $\mathrm{Pd}$ and $\mathrm{Al}$ atoms within the $\left[\mathrm{Pd}_{2} \mathrm{Al}_{3}\right]^{\delta-}$ polyanion was observed. Magnetic measurements revealed an anomaly in the dc susceptibility data and intermediate valent $\mathrm{Yb}$ at higher temperature, as observed from the effective magnetic moment. The proposed valence phase transition was also observed as a $\lambda$ type anomaly in heat capacity measurements $(T=108.4(1) \mathrm{K})$, however, no systematic shift of the $\lambda$-peak was observed in field dependent heat capacity measurements. An antiferromagnetic ordering at this temperature, however, could be excluded, based on field-dependent susceptibility measurements and magnetization isotherms. No dynamic phenomenon was observed in ac susceptibility measurements, excluding e.g. spin-glass behavior. Subsequent temperature dependent single-crystal and powder X-ray diffraction experiments indicated a steep increase in the length of the $c$ axis around $T=110 \mathrm{~K}$ upon cooling. However, no structural phase transition was found via single-crystal diffraction experiments conducted at $90 \mathrm{~K}$. The anomaly was also observed in other physical measurements of e.g. the electrical resistivity, indicating a clear change in the electronic structure of the material. X-ray photoelectron spectroscopy conducted at room temperature shows the presence of both, $\mathrm{Yb}^{2+}$ and $\mathrm{Yb}^{3+}$, underlining the mixed-valent state. Members of the solid solution $\mathrm{Yb}_{1-x} \mathrm{Ca}_{x} \mathrm{Pd}_{2} \mathrm{Al}_{3}(x=0.33,0.67,1)$ were finally used to further study the charge ordering and the present temperature induced valence phase transition.

\section{Introduction}

In the field of rare-earth element chemistry, the predominant oxidation state of the lanthanoides is the trivalent one. Cerium, praseodymium or terbium exhibit an additional tetravalent oxidation state while for samarium, europium and ytterbium an additional divalent oxidation state exists. ${ }^{1-3}$ The resulting physical phenomena are numerous, e.g. mixed/intermediate valences in compounds with inequivalent crystallographic cationic sites $\left(\mathrm{Eu}_{3} \mathrm{O}_{4},{ }^{4-6} \quad \mathrm{HP}^{4} \mathrm{~Tb}_{3} \mathrm{O}_{5},{ }^{7} \quad \mathrm{EuSr}_{2} \mathrm{Bi}_{2} \mathrm{~S}_{4} \mathrm{~F}_{4}\right.$ and

${ }^{a}$ Institut für Anorganische und Analytische Chemie, Westfälische Wilhelms-Universität Münster, Corrensstraße 30, D-48149 Münster, Germany. E-mail: ocjanka@ uni-muenster.de

${ }^{b}$ Department Chemie, Ludwig-Maximilians-Universität München, Butenandtstrasse 513 (Haus D), D-81377 München, Germany

${ }^{c}$ Center for Soft Nanoscience, Westfälische Wilhelms-Universität Münster, Busso-PeusStraße 10, D-48149 Münster, Germany

$\dagger$ Electronic supplementary information (ESI) available. CCDC 1868211, 1868849, 1875396, 1880784-1880786, 1892594, 1892597-1892598, 1895369-1895370 and 1910744. For ESI and crystallographic data in CIF or other electronic format see DOI: $10.1039 / \mathrm{c} 9 \mathrm{sc} 04437 \mathrm{j}$
$\mathrm{Eu}_{2} \mathrm{SrBi}_{2} \mathrm{~S}_{4} \mathrm{~F}_{4},{ }^{8} \mathrm{Ce}_{2} \mathrm{Rh}_{3} \mathrm{Sn}_{5}$ (ref. 9)), inhomogeneous mixed valence states $\left(\mathrm{Sm}_{3} \mathrm{~S}_{4},{ }^{10,17} \mathrm{Eu}_{3} \mathrm{~S}_{4},{ }^{10}\right.$ or EuPtP $\left.{ }^{11}\right)$ as well as intermetallic valence fluctuating materials $\left(\mathrm{CeAl}_{3},{ }^{12,13} \mathrm{Yb}_{4} \mathrm{Pt}_{9} \mathrm{Ga}_{24},{ }^{14}\right.$ $\left.\mathrm{CeMo}_{2} \mathrm{Si}_{2} \mathrm{C},{ }^{15} \mathrm{CeRu}_{1-x} \mathrm{Ni}_{x} \mathrm{Al}^{16}\right) .{ }^{18}$ Kondo states or heavy fermion behavior are other prominent physical features, attributed to valence instabilities. Temperature or pressure dependent valence phase transitions in contrast are rather rare. Transitions of this type are found e.g. in metallic Ce, ${ }^{19}$ in the double perovskites $\mathrm{Ba}_{2} \operatorname{PrRu}_{1-x} \mathrm{Ir}_{x} \mathrm{O}_{6}$ (ref. 20) or in the samarium monochalcogenides SmCh $\left(\mathrm{Ch}=\mathrm{S}\right.$, Se, Te). ${ }^{21,22}$ In EuPtP two new pressure induced valence ordered structures were observed, ${ }^{23}$ while $\mathrm{EuCo}_{2} \mathrm{As}_{2}$ (ref. 24) and $\mathrm{YbAl}_{3}$ (ref. 25) exhibit pressure dependent shifts of their valence. Finally, intermetallic $\operatorname{EuPd}_{2}$ $\mathrm{Si}_{2}\left(T_{\text {trans }} \sim 200 \mathrm{~K}\right)^{26}$ and $\mathrm{Eu}_{2} \mathrm{Pt}_{6} \mathrm{Al}_{15}\left(T_{\text {trans }} \sim 45 \mathrm{~K}\right)^{27}$ as well as the solid solutions $\mathrm{CeNi}_{1-x} \mathrm{Co}_{x} \mathrm{Sn}\left(x=0.4 ; T_{\text {trans }} \sim 95 \mathrm{~K}\right)^{28}$ and $\mathrm{Yb}_{x} \mathrm{In}_{1-x} \mathrm{Cu}_{2}\left(x=0.4 ; T_{\text {trans }} \sim 50 \mathrm{~K}\right)^{29-31}$ exhibit temperature dependent valence phase transitions.

Herein, we report on the temperature induced valence phase transition in intermetallic $\mathrm{YbPd}_{2} \mathrm{Al}_{3}\left(\mathrm{YNi}_{2} \mathrm{Al}_{3}\right.$ type, ${ }^{32} \mathrm{P6} / \mathrm{mmm}, Z$ $=3$ ) from intermediate valent $\mathrm{Yb}$ at high temperatures to divalent $\mathrm{Yb}$ at low temperatures. Upon localization of an 
electron, a paramagnetic to Pauli-paramagnetic transition occurs at $T_{\text {anomaly }}=110(1) \mathrm{K}$, which can be observed as a drastic drop in the magnetic susceptibility. The $\mathrm{Yb}^{3+} \rightarrow \mathrm{Yb}^{2+}$ valence phase transition is furthermore visible in an expansion of the $c$ lattice parameter during cooling, observed in temperature dependent single-crystal and powder X-ray diffraction experiments of $\mathrm{YbPd}_{2} \mathrm{Al}_{3}$ and the solid solution $\mathrm{Yb}_{1-x} \mathrm{Ca}_{x} \mathrm{Pd}_{2} \mathrm{Al}_{3}(x=$ $0.33,0.67,1)$. The (field dependent) specific heat capacity and the electrical resistivity were investigated to underline the proposed valence phase transition, XPS measurements underline the mixed-valent $\mathrm{Yb}$ state at room temperature.

\section{Experimental section}

\subsection{Synthesis}

Starting materials for the syntheses of $\mathrm{YbPd}_{2} \mathrm{Al}_{3}$ and the members of the $\mathrm{Yb}_{1-x} \mathrm{Ca}_{x} \mathrm{Pd}_{2} \mathrm{Al}_{3}$ series $(x=0.33,0.67)$ as well as $\mathrm{CaPd}_{2} \mathrm{Al}_{3}$ were ingots of ytterbium (Smart Elements, 99.99\%), calcium pieces (Alfa Aesar, 99.5\%), palladium sheets (Agosi, 99.99\%), and aluminum turnings (Koch chemicals, 99.99\%). The calcium ingots were stored under argon; surface impurities were removed mechanically prior to the synthesis. The elements were weighed in the respective atomic ratios and arc-welded ${ }^{33}$ in tantalum tubes under a dried argon atmosphere of about 800 mbar. The argon gas was purified over titanium sponge ( $873 \mathrm{~K})$, molecular sieves and silica gel prior to use. The metal tubes were placed in the water-cooled sample chamber of a highfrequency furnace (Hüttinger Elektronik, Freiburg, type TIG 1.5/300 and TIG 5.0/300) in flowing argon. ${ }^{34}$ The samples were rapidly heated to $1473 \mathrm{~K}$, kept at that temperature for $10 \mathrm{~min}$, annealed for another $5 \mathrm{~h}$ at $1023 \mathrm{~K}$ and finally rapidly quenched by switching off the high-frequency generator. The temperature was controlled using a radiation pyrometer (Metis MS09, Sensortherm, accuracy: $\pm 50 \mathrm{~K}$ ). In all cases, the compounds could easily be separated from the ampoules and no reactions with the container material were observed.

\subsection{X-ray diffraction}

The polycrystalline $\mathrm{Yb}_{1-x} \mathrm{Ca}_{x} \mathrm{Pd}_{2} \mathrm{Al}_{3}(x=0,0.33,0.67,1)$ samples were characterized by Guinier patterns (imaging plate detector, Fujifilm BAS-1800) with $\mathrm{Cu} \mathrm{K} \alpha 1$ radiation and $\alpha$-quartz $(a=$ 491.30 and $c=540.46 \mathrm{pm}$ ) as an internal standard. The lattice parameters were deduced from least-squares fits of the Guinier data $^{35}$ using the structural models determined by singlecrystal X-ray diffraction experiments. For the solid solution $\mathrm{Yb}_{1-x} \mathrm{Ca}_{x} \mathrm{Pd}_{2} \mathrm{Al}_{3}(x=0,0.33,0.67,1)$ Vegard's law-like behavior was observed for the unit cell volume along with a linear trend of the hexagonal lattice parameters (Table 1). Temperature dependent powder X-ray diffraction experiments between 10 and $300 \mathrm{~K}$ were conducted on a Huber G670 Guinier Imaging Plate diffractometer (Co K $\alpha 1$ radiation, Ge-111 monochromator, silicon as external standard) with Low Temperature Device 670.4 and closed cycle $\mathrm{He}$ cryostat (Lakeshore temperature controller, model 331). The lattice parameters of the temperature dependent measurements are listed in Table S1. $\dagger$
Table 1 Lattice parameters of the $\mathrm{Yb}_{1-x} \mathrm{Ca}_{x} \mathrm{Pd}_{2} \mathrm{Al}_{3}$ series $(x=0,0.33$, $0.67,1)$, space group $P 6 / \mathrm{mmm}, Z=3$, determined by temperature dependent single-crystal $X$-ray diffraction and by room temperature Guinier powder X-ray diffraction

\begin{tabular}{|c|c|c|c|c|}
\hline Compound & $T(\mathrm{~K})$ & $a(\mathrm{pm})$ & $c(\mathrm{pm})$ & $V\left(\mathrm{~nm}^{3}\right)$ \\
\hline $\mathrm{YbPd}_{2} \mathrm{Al}_{3}{ }^{a}$ & $90(2)$ & $928.02(6)$ & $422.22(3)$ & 0.3149 \\
\hline $\mathrm{YbPd}_{2} \mathrm{Al}_{3}{ }^{a}$ & $140(2)$ & $928.02(6)$ & $419.56(3)$ & 0.3129 \\
\hline $\mathrm{YbPd}_{2} \mathrm{Al}_{3}^{a}$ & $300(2)$ & $929.56(7)$ & $420.16(3)$ & 0.3144 \\
\hline $\mathrm{YbPd}_{2} \mathrm{Al}_{3}^{b}$ & RT & $928.9(2)$ & $420.25(9)$ & 0.3140 \\
\hline $\mathrm{Yb}_{0.68(1)} \mathrm{Ca}_{0.32(1)} \mathrm{Pd}_{2} \mathrm{Al}_{3}{ }^{a}$ & RT & $930.98(7)$ & $421.40(3)$ & 0.3163 \\
\hline $\mathrm{Yb}_{0.67} \mathrm{Ca}_{0.33} \mathrm{Pd}_{2} \mathrm{Al}_{3}^{b}$ & $\mathrm{RT}$ & $932.3(1)$ & $421.73(4)$ & 0.3174 \\
\hline $\mathrm{Yb}_{0.34(1)} \mathrm{Ca}_{0.66(1)} \mathrm{Pd}_{2} \mathrm{Al}_{3}{ }^{a}$ & $\mathrm{RT}$ & $933.53(7)$ & $422.66(3)$ & 0.3190 \\
\hline $\mathrm{Yb}_{0.33} \mathrm{Ca}_{0.67} \mathrm{Pd}_{2} \mathrm{Al}_{3}{ }^{b}$ & RT & $934.1(2)$ & $423.0(1)$ & 0.3197 \\
\hline $\mathrm{CaPd}_{2} \mathrm{Al}_{3}{ }^{a}$ & RT & $936.28(6)$ & $423.96(3)$ & 0.3219 \\
\hline $\mathrm{CaPd}_{2} \mathrm{Al}_{3}{ }^{b}$ & $\mathrm{RT}$ & $936.3(1)$ & $423.86(5)$ & 0.3218 \\
\hline
\end{tabular}

Small single-crystals of the $\mathrm{Yb}_{1-x} \mathrm{Ca}_{x} \mathrm{Pd}_{2} \mathrm{Al}_{3}(x=0,0.33,0.67$, 1) series were selected from the obtained samples. The crystals were glued to thin quartz fibers using beeswax and investigated by Laue photographs taken on a Buerger camera (white molybdenum radiation; imaging plate technique, Fujifilm, BAS$1800)$ in order to check their quality. Temperature dependent intensity data sets of $\mathrm{YbPd}_{2} \mathrm{Al}_{3}$ were collected with a Stoe StadiVari four-circle diffractometer (Mo K $\alpha$ radiation; $\lambda=71.073$ pm; $\mu$-source; oscillation mode; hybrid-pixel-sensor, Dectris Pilatus $100 \mathrm{~K}$ (ref. 36)) with an open Eulerian cradle setup. Additional measurements at room temperature were conducted on a Stoe IPDS-II image plate system (graphite monochromatized Mo $\mathrm{K} \alpha$ radiation; $\lambda=71.073 \mathrm{pm}$; oscillation mode). Numerical absorption corrections along with scaling (for the StadiVari data sets) were applied. To obtain further information about possible site preferences ( $\mathrm{Yb}: \mathrm{Ca})$ within the solid solution, four independent single-crystals of the samples with the nominal compositions $\mathrm{Yb}_{0.33} \mathrm{Ca}_{0.67} \mathrm{Pd}_{2} \mathrm{Al}_{3}$ and $\mathrm{Yb}_{0.33} \mathrm{Ca}_{0.67} \mathrm{Pd}_{2} \mathrm{Al}_{3}$ were collected each (Table $\mathrm{S} 2 \dagger$ ). Details about the data collection and the crystallographic parameters are summarized in Tables S3-S6. $\dagger$

CCDCs 1868211, 1868849, 1875396, 1880784-1880786, 1892594, 1892597-1892598, 1895369-1895370 and 1910744 contain the supplementary crystallographic data for this paper. $\dagger$

\subsection{Physical property investigations}

Susceptibility measurements. Magnetic susceptibility measurements were conducted on a Quantum Design Physical Property Measurement System (PPMS). For the dc-susceptibility measurements, powdered samples of the $\mathrm{Yb}_{1-x} \mathrm{Ca}_{x} \mathrm{Pd}_{2} \mathrm{Al}_{3}(x=$ $0,0.33,0.67,1)$ series were loaded in polyethylene $(\mathrm{PE})$ capsules and attached to the sample holder rod of a Vibrating Sample Magnetometer (VSM) unit for measuring the magnetization $M(T, H)$. The samples were investigated in the temperature range of 3-395 K with external magnetic fields up to $90 \mathrm{kOe} . \mathrm{YbPd}_{2} \mathrm{Al}_{3}$ was further investigated by ac-magnetic susceptibility measurements. Therefore, the powdered sample was enclosed in a thin-walled gelatin capsule attached to a drinking straw 
(Quantum Design). In-phase $\chi^{\prime}(\omega, T)$ and out-of-phase susceptibilities $\chi^{\prime \prime}(\omega, T)$ were recorded in the temperature range of 97 to $117 \mathrm{~K}$ with external dc magnetic fields up to $20 \mathrm{kOe}$ and one data point every $0.5 \mathrm{~K}$.

Heat capacity. For the heat capacity measurements of $\mathrm{YbPd}_{2} \mathrm{Al}_{3}$, one piece of the sample was fixed to a pre-calibrated heat capacity puck using Apiezon $\mathrm{N}$ grease and investigated in the temperature range of 2-300 K. Additionally field dependent heat capacity measurement with external fields of 10, 50 and 90 kOe were conducted.

Electrical resistivity. For the resistivity measurements, a polycrystalline sample of $\mathrm{YbPd}_{2} \mathrm{Al}_{3}$ was cold-pressed into a pellet with $\emptyset=4.5 \mathrm{~mm}, d=1.2 \mathrm{~mm}$ and sintered at $823 \mathrm{~K}$ for $14 \mathrm{~d}$ in an evacuated silica ampoules in order to reduce grain boundaries. The resistivity measurement was carried out in the AC transport mode ${ }^{37}$ of the PPMS. The ACT puck was modified by a van-der-Pauw ${ }^{37}$ press contact assembly purchased from Wimbush Science \& Technology. The probes are spring contacts, gold plated over nickel; the distance between the pins was set to $2 \mathrm{~mm}$. The resistivity was measured between $2-300 \mathrm{~K}$ with a data point every $1 \mathrm{~K}$ up to $95 \mathrm{~K}$, every $0.1 \mathrm{~K}$ between 95.1 and $119.9 \mathrm{~K}$ and a data point every $2 \mathrm{~K}$ up to $300 \mathrm{~K}$. A maximum current of $10 \mathrm{~mA}$ was used; the AC frequency was set to $29 \mathrm{~Hz}$ with a measurement time of $1 \mathrm{~s}$. The recorded data of channel 1 \& 2 was converted according to the van-der-Pauw equation given in the Quantum Design Application Note 1076-304.

\subsection{X-ray photoelectron spectroscopy (XPS)}

$\mathrm{X}$-ray photoelectron spectra were measured using an Axis-Ultra spectrometer (Kratos, Manchester, UK) in ultrahigh vacuum (pressure $<10^{-7} \mathrm{~Pa}$ ). Monochromatic $\mathrm{Al} \mathrm{K} \alpha$ radiation $(h \nu=$ $1486.6 \mathrm{eV}$ ) was used with a $12 \mathrm{kV}$ accelerating voltage and $10 \mathrm{~mA}$ emission current. The charge neutralizer was run with a filament current of $1.82 \mathrm{~A}$, a charge balance of $2.25 \mathrm{~V}$ and a filament bias of $1.0 \mathrm{~V}$. A pass energy filter of $40 \mathrm{eV}$ was applied to the hemispherical analyzer (electrostatic lens mode), enabling high-energy resolution for narrow scans with a step size of $0.1 \mathrm{eV}$ at a dwell time of $4 \mathrm{~s}$. Cold-pressed pellets $(\varnothing=4.5 \mathrm{~mm}$, $d=1.0-1.5 \mathrm{~mm}$ ) of polycrystalline $\mathrm{YbPd}_{2} \mathrm{Al}_{3}, \mathrm{Yb}_{0.67} \mathrm{Ca}_{0.33} \mathrm{Pd}_{2} \mathrm{Al}_{3}$, $\mathrm{Yb}_{0.33} \mathrm{Ca}_{0.67} \mathrm{Pd}_{2} \mathrm{Al}_{3}$, and $\mathrm{CaPd}_{2} \mathrm{Al}_{3}$ along with a piece of elemental palladium were attached to the XPS sample holder using conductive carbon tape. An area of about $1 \times 2 \mathrm{~mm}^{2}$ on the samples surfaces were irradiated at an X-ray incidence angle of $30^{\circ}$ relative to the sample normal. Due to different static charge phenomena of the samples, the $\mathrm{C} 1 \mathrm{~s}$ signal, caused by organic surface contaminations, was used as an internal reference and its binding energy was set to $285.0 \mathrm{eV}$ (referenced to the Fermi level) for all samples. The peak positions were determined by Gaussian fits of the spectra and are listed in Table 2 .

\section{Results and discussion}

\subsection{Structure refinement}

A selected single-crystal of $\mathrm{YbPd}_{2} \mathrm{Al}_{3}$ was first measured at $300 \mathrm{~K}$ and a careful analysis of the obtained data set indicated
Table 2 Binding energies determined by XPS for $\mathrm{YbPd}_{2} \mathrm{Al}_{3}$, $\mathrm{Yb}_{0.67} \mathrm{Ca}_{0.33} \mathrm{Pd}_{2} \mathrm{Al}_{3}, \mathrm{Yb}_{0.33} \mathrm{Ca}_{0.67} \mathrm{Pd}_{2} \mathrm{Al}_{3}$ and $\mathrm{CaPd}_{2} \mathrm{Al}_{3}$ along with data from the literature. Standard deviations are within $\pm 0.2 \mathrm{eV}$

\begin{tabular}{llllll}
\hline & $\mathrm{Yb}^{0} 4 \mathrm{~d}$ & $\mathrm{Yb}^{2+} 4 \mathrm{~d}$ & $\mathrm{Yb}^{3+} 4 \mathrm{~d}$ & $\mathrm{Pd} 3 \mathrm{~d}$ & $\mathrm{Ca} 2 \mathrm{p}$ \\
\hline $\mathrm{YbPd}_{2} \mathrm{Al}_{3}{ }^{a}$ & - & 182.5 & 185.6 & 335.1 & - \\
$\mathrm{Yb}_{0.67} \mathrm{Ca}_{0.33} \mathrm{Pd}_{2} \mathrm{Al}_{3}{ }^{a}$ & - & 182.4 & 185.7 & 335.3 & 347.3 \\
$\mathrm{Yb}_{0.33} \mathrm{Ca}_{0.67} \mathrm{Pd}_{2} \mathrm{Al}_{3}{ }^{a}$ & - & 182.8 & 185.9 & 335.3 & 347.3 \\
$\mathrm{CaPd}_{2} \mathrm{Al}_{3}{ }^{a}$ & - & - & - & 335.4 & 347.3 \\
$\mathrm{Yb}^{71}{ }$ & 181.2 & - & - & - & - \\
$\mathrm{Yb}_{2} \mathrm{O}_{3}$ (ref. 71) & - & - & 185.4 & - & - \\
$\mathrm{Pd}^{a}{ }^{72}$ & - & - & - & 335.5 & - \\
$\mathrm{Pd}^{72}$ & - & - & - & 335.2 & - \\
$\mathrm{Pd}^{73}$ & - & - & - & 335.3 & - \\
$\mathrm{PdAl}_{3}$ (ref. 72) & - & - & - & 337.7 & - \\
$\mathrm{CaO}^{65}$ & - & - & - & - & 347.1 \\
$\mathrm{CaCO}_{3}$ (ref. 66) & - & - & - & - & 347.1 \\
$\mathrm{CaMoO}_{4}$ (ref. 67) & - & - & - & - & 347.4 \\
${ }^{a} \mathrm{This} \mathrm{work.}$ & & & & &
\end{tabular}

a hexagonal primitive lattice. During the refinement, space group $P 6 / \mathrm{mmm}$ was found to be correct; isotypism with the $\mathrm{YNi}_{2} \mathrm{Al}_{3}$ type structure ${ }^{32}$ was already evident from the Guinier powder pattern and from a systematic check of the Pearson database. ${ }^{38}$ The structure solution was conducted using the SuperFlip algorithm. ${ }^{39}$ All structures were refined on $F^{2}$ with anisotropic displacement parameters for all atoms using Jana2006. ${ }^{40,41}$ As a check for the correct composition, the occupancy parameters were refined in a separate series of leastsquares cycles. All sites were fully occupied within three standard deviations with exception of the solid solution (vide infra). No significant residual peaks were evident in the final difference Fourier syntheses. The final positional parameters and interatomic distances are listed in Tables S5 and S6. $\uparrow$ The Yb:Ca site occupancies of the single-crystals obtained for members of the solid solutions are additionally listed in Table $\mathbf{S 2 . \dagger}$ Due to the unusual anomaly visible in the susceptibility measurement (vide infra) additional data sets of $\mathrm{YbPd}_{2} \mathrm{Al}_{3}$ were recorded at 140 and $90 \mathrm{~K}$. Data sets of the single-crystals obtained from the samples with nominal compositions $\mathrm{Yb}_{0.67} \mathrm{Ca}_{0.33} \mathrm{Pd}_{2} \mathrm{Al}_{3}$ and $\mathrm{Yb}_{0.33} \mathrm{Ca}_{0.67} \mathrm{Pd}_{2} \mathrm{Al}_{3}$ as well as $\mathrm{CaPd}_{2} \mathrm{Al}_{3}$ were recorded at room temperature. The obtained data sets of all measurements were handled as described above; the results will be discussed in the crystal chemistry section below.

\subsection{Temperature dependent powder X-ray diffraction}

Guinier powder patterns were recorded of all prepared samples to check for phase purity and refine the lattice parameters (Table 1). Additionally, temperature dependent powder X-ray diffraction patterns of $\mathrm{YbPd}_{2} \mathrm{Al}_{3}$ were recorded between 10$300 \mathrm{~K}$ upon cooling with intervals of $10 \mathrm{~K}$ from $10-90$ and 120$300 \mathrm{~K}$, between 90 and $120 \mathrm{~K}$ intervals of $5 \mathrm{~K}$ were used. In order to obtain the powder lattice parameters, the unit cell dimensions of the $90 \mathrm{~K}$ single-crystal measurement were used as starting point and refined using WinPLOTR ${ }^{\mathbf{4}}$ of the FullProf Suite. ${ }^{43}$ The lattice parameters and the unit cell volumes obtained from these measurements are listed in Table $\mathrm{S} 2 \uparrow$ and 


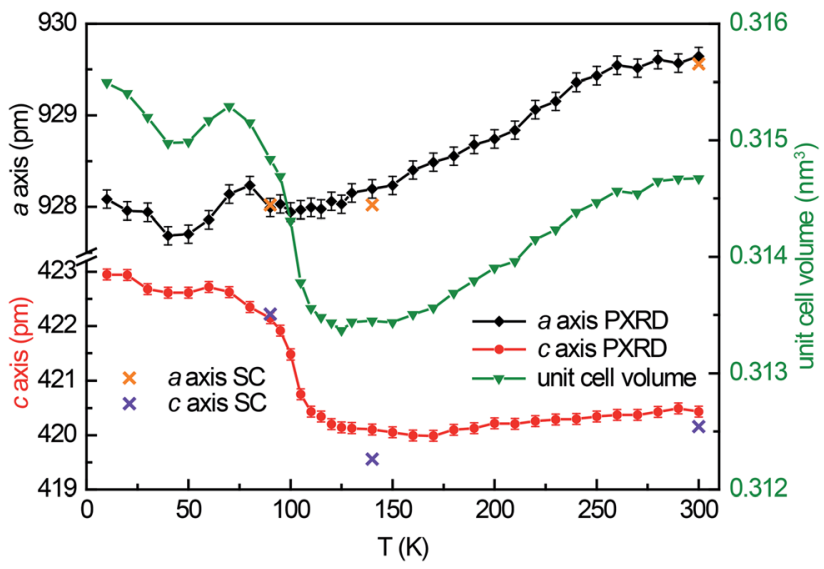

Fig. 1 Temperature dependent lattice parameters of $\mathrm{YbPd}_{2} \mathrm{Al}_{3} \mathrm{Ob}$ tained from temperature dependent powder $X$-ray diffraction experiments upon cooling from 300 to $10 \mathrm{~K}$ and from single-crystal $X$-ray diffraction experiments.

depicted in Fig. 1, along with the unit cell parameters obtained from the single-crystal X-ray diffraction experiments. With decreasing temperature, both $a$ and $c$ axis initially contract until $\sim 120 \mathrm{~K}$. At lower temperatures, however, a quite drastic expansion of $\sim 3 \mathrm{pm}$ for the $c$ axis is visible, starting around 105 $\mathrm{K}$. The $a$ axis in contrast does not show this effect.

\subsection{Crystal chemistry}

$\mathrm{YbPd}_{2} \mathrm{Al}_{3}$ and the other representatives of the solid solution $\mathrm{Yb}_{1-x} \mathrm{Ca}_{x} \mathrm{Pd}_{2} \mathrm{Al}_{3}(x=0.33,0.67,1)$ all crystallize in the hexagonal crystal system with space group $P 6 / \mathrm{mmm}$ in the $\mathrm{YNi}_{2} \mathrm{Al}_{3}$ type structure. No superstructure reflections as in $\operatorname{ErPd}_{2} \mathrm{Al}_{3}$ (ref. 44) were observed. The structure description and discussion in the following paragraphs is based on the $300 \mathrm{~K}$ measurement of $\mathrm{YbPd}_{2} \mathrm{Al}_{3}$. The crystal structure can be described by a polyanionic $\left[\mathrm{Pd}_{2} \mathrm{Al}_{3}\right]^{\delta-}$ framework with two crystallographically independent $\mathrm{Yb}$ atoms residing in the cavities of the polyanion (Fig. 2). Within the polyanionic network short heteroatomic Pd-

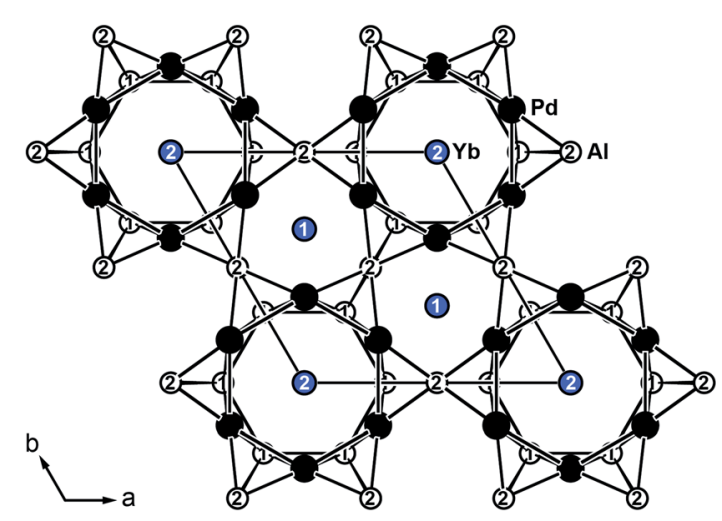

Fig. 2 Extended unit cell of hexagonal $\mathrm{YbPd}_{2} \mathrm{Al}_{3} \quad\left(\mathrm{YNi}_{2} \mathrm{Al}_{3}\right.$ type) depicted along [001]. $\mathrm{Yb}$ atoms are shown in blue, $\mathrm{Pd}$ atoms in black and $\mathrm{Al}$ atoms in white.
$\mathrm{Al}$ distances of $254(\mathrm{Pd}-\mathrm{Al} 2)$ and $259 \mathrm{pm}(\mathrm{Pd}-\mathrm{Al} 1)$ are found along with longer homoatomic Al-Al (278 and 283 pm) and Pd$\mathrm{Pd}$ distances $(299 \mathrm{pm})$. The observed interatomic $\mathrm{Pd}-\mathrm{Al}$ distances are in line with those found in binary $\mathrm{PdAl}^{45}(264 \mathrm{pm}$, CsCl type), $\mathrm{PdAl}_{2}$ (ref. 46) (255 pm, $\mathrm{Co}_{2} \mathrm{Si}$ type), $\mathrm{Pd}_{5} \mathrm{Al}_{3}$ (ref. 46) (250-287 pm, $\mathrm{Rh}_{5} \mathrm{Ge}_{3}$ type) or ternary $\mathrm{YbPdAl}^{47,48}$ (256-267 pm, TiNiSi type) and $\mathrm{Yb}_{8} \mathrm{Pd}_{24} \mathrm{Al}^{49}$ (253 pm, $\mathrm{Ce}_{8} \mathrm{Pd}_{24} \mathrm{Sb}$ type). The homoatomic distances are in line with those reported e.g. for elemental $\mathrm{Al}^{50}$ (286 pm), binary $\mathrm{Pd}_{5} \mathrm{Al}_{3}$ (ref. 46) $(\mathrm{Pd}-\mathrm{Pd}=271-$ $306 \mathrm{pm})$ or ternary $\mathrm{Yb}_{8} \mathrm{Pd}_{24} \mathrm{Al}^{49}(\mathrm{Pd}-\mathrm{Pd}=266-307 \mathrm{pm})$. The two independent $\mathrm{Yb}$ atoms both reside in a sixfold capped hexagonal prism, depicted in Fig. 3. The interatomic $\mathrm{Yb}-\mathrm{Pd}$ distances range from 300-317 pm, the $\mathrm{Yb}-\mathrm{Al}$ contacts from $324-352 \mathrm{pm}$. Both are in the same range as those in e.g. $\mathrm{YbPdAl}^{47,48}(\mathrm{Yb}-\mathrm{Pd}=$ 286-303 pm, $\mathrm{Yb}-\mathrm{Al}=$ 306-326 pm).

Upon cooling, the unit cell contracts (vide supra), therefore the respective interatomic distances contract accordingly when cooling from 300 to $140 \mathrm{~K}$. When decreasing the temperature further to $90 \mathrm{~K}$, the $\mathrm{Yb} 1-\mathrm{Al} 1, \mathrm{Yb} 1-\mathrm{Al} 2, \mathrm{Yb} 2-\mathrm{Al} 1$ (Fig. $\mathrm{S} 1, \dagger$ top) and $\mathrm{Yb} 1-\mathrm{Pd}$ (Fig. S1, $\dagger$ bottom) distances increase, also in line with the observed unit cell changes. The interatomic Yb2-Pd and Pd-Pd distances in contrast slightly decrease (Fig. S1, $\uparrow$ bottom). This, however, is not surprising since they form the caps of the hexagonal prism. Upon expansion of the prism along [001] the caps move towards the center of the prisms, shortening the respective $\mathrm{Yb} 2-\mathrm{Pd}$ and $\mathrm{Pd}-\mathrm{Pd}$ distances. It is important to note again, that no structural transition was observed, the hexagonal space group symmetry remains at $90 \mathrm{~K}$.

For the members of the solid solutions $\mathrm{Yb}_{1-x} \mathrm{Ca}_{x} \mathrm{Pd}_{2} \mathrm{Al}_{3}$ with $x$ $=0.33$ and 0.67 , mixing of $\mathrm{Yb}$ and $\mathrm{Ca}$ on the two crystallographic Yb sites ( $1 a$ and $2 d$ ) was observed. For both compositions, four single-crystals each were selected and investigated, showing the
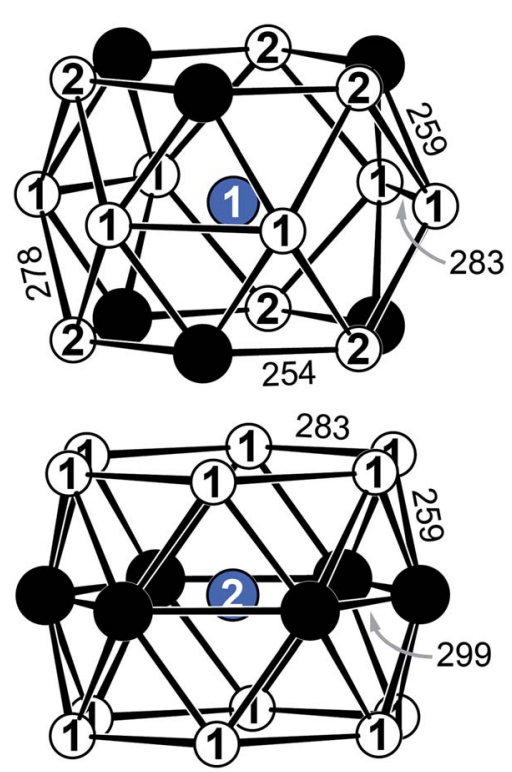

Fig. 3 Sixfold capped hexagonal prisms surrounding the two crystallographically independent $\mathrm{Yb}$ atoms in $\mathrm{YbPd}_{2} \mathrm{Al}_{3}$. Interatomic distances are given in pm. $\mathrm{Yb}$ atoms are shown in blue, $\mathrm{Pd}$ atoms in black and $\mathrm{Al}$ atoms in white. 
same $\mathrm{Yb} / \mathrm{Ca}$ distribution. For nominal $\mathrm{Yb}_{0.67} \mathrm{Ca}_{0.33} \mathrm{Pd}_{2} \mathrm{Al}_{3}$ a distribution of $80(1) \% \mathrm{Yb}$ and $20(1) \% \mathrm{Ca}$ on the $2 d$ site and $46(1) \% \mathrm{Yb}$ and $54(1) \%$ Ca on the $1 a$ site was observed resulting to a refined composition of $\mathrm{Yb}_{0.68(1)} \mathrm{Ca}_{0.32(1)} \mathrm{Pd}_{2} \mathrm{Al}_{3}$ for all compounds. For nominal $\mathrm{Yb}_{0.33} \mathrm{Ca}_{0.67} \mathrm{Pd}_{2} \mathrm{Al}_{3}$ a distribution of $44(1) \% \mathrm{Yb}$ and $56(1) \% \mathrm{Ca}$ on the $2 d$ site and 15(1)\% Yb and 85(1)\% Ca on the $1 a$ site was found leading to $\mathrm{Yb}_{0.34(1)} \mathrm{Ca}_{0.66(1)} \mathrm{Pd}_{2} \mathrm{Al}_{3}$ (Table S2 $\dagger$ ). This narrow distribution is very intriguing and points towards a potential charge ordering.

\subsection{Physical properties}

A powdered sample of $\mathrm{YbPd}_{2} \mathrm{Al}_{3}$ was first investigated by dcmagnetic susceptibility measurements between $3-300 \mathrm{~K}$ in zero-field-cooled mode (ZFC) at $10 \mathrm{kOe}$. The susceptibility $\chi$ and its inverse $\chi^{-1}$ are depicted in Fig. 4 (top). With decreasing temperature the susceptibility starts to rise, followed by a sharp decrease at $T_{\text {anomaly }}=110(1) \mathrm{K}$. The temperature of the anomaly was determined from the maximum of $\mathrm{d} \chi / \mathrm{d} T$, plotted in blue. Below $25 \mathrm{~K}$ the susceptibility rises again reaching $\chi=0.0079(1)$ emu $\mathrm{mol}^{-1}$ at $3 \mathrm{~K}$. This feature is likely to be caused by traces of paramagnetic impurities such as $\mathrm{Yb}_{2} \mathrm{O}_{3}$ that orders antiferromagnetically at $2.3 \mathrm{~K}^{51}$ In order to determine the effective magnetic moment, a fit of the inverse magnetic susceptibility between 175 and $300 \mathrm{~K}$ using the modified Curie-Weiss law with $\chi_{0}=-1.28(1) \times 10^{-4} \mathrm{emu} \mathrm{mol}^{-1}$ (obtained from $\mathrm{CaPd}_{2} \mathrm{Al}_{3}$ at 300 $\mathrm{K})$ was conducted. The effective magnetic moment is $\mu_{\text {eff }}=$ 2.75(1) $\mu_{\mathrm{B}}$, in line with the observations of the temperature dependence of the effective magnetic moment (vide infra). The Weiss constant is $\theta_{\mathrm{P}}=0.9(2) \mathrm{K}$, suggesting no dominant magnetic interaction in the paramagnetic temperature regime. In order to understand the behavior around $T=110 \mathrm{~K}$, the temperature dependent effective magnetic moment per $\mathrm{Yb}$ atom was calculated according to

$$
\mu_{\text {eff }}=\sqrt{8 \chi T}
$$

and is plotted in Fig. 4 (middle, top). The effective magnetic moment initially increases almost linear with increasing temperature starting at $\mu_{\mathrm{eff}}=0.43(1) \mu_{\mathrm{B}}$ at $3 \mathrm{~K}$ before again a rapid increase around $T_{\text {anomaly }}=110(1) \mathrm{K}$ is observed. Above $150 \mathrm{~K}$ the moment saturates with $\mu_{\text {eff }}=2.72(1) \mathrm{K}$ at $300 \mathrm{~K}$ measured at $10 \mathrm{kOe}\left(\mu_{\text {eff }}=2.59(5) \mathrm{K}\right.$ at $300 \mathrm{~K}$ measured at $50 \mathrm{Oe}$, see Fig. S6 $\dagger$ ). The magnetization isotherms recorded at 3 and 10 $\mathrm{K}$ are slightly curved, the isotherm at $50 \mathrm{~K}$ is linear, typical for a paramagnetic material, while the isotherm recorded at $150 \mathrm{~K}$ finally exhibits a much stronger increase, in line with a higher contribution of paramagnetic $\mathrm{Yb}^{3+}$ at this temperature (Fig. 4, middle, bottom). The saturation magnetization at $3 \mathrm{~K}$ and 80 kOe is $\mu_{\text {sat }}=0.05(2) \mu_{\mathrm{B}}$, which is drastically lower compared to the expected saturation magnetization of $4 \mu_{\mathrm{B}}$ according to $g_{J} \times$ $J$ for $\mathrm{Yb}^{3+}$. The reported magnetic behavior (reduced effective magnetic moment and low saturation magnetization), along with the structural investigations, can only be explained if $\mathrm{YbPd}_{2} \mathrm{Al}_{3}$ contains partially paramagnetic $\mathrm{Yb}^{3+}$ cations $\left(4 \mathrm{f}^{13}\right)$ at higher temperatures, which are reduced to diamagnetic $\mathrm{Yb}^{2+}$ cations $\left(4 \mathrm{f}^{14}\right)$ below $T_{\text {anomaly }}=110(1) \mathrm{K}$ by a spontaneous electron localization from the conduction band.
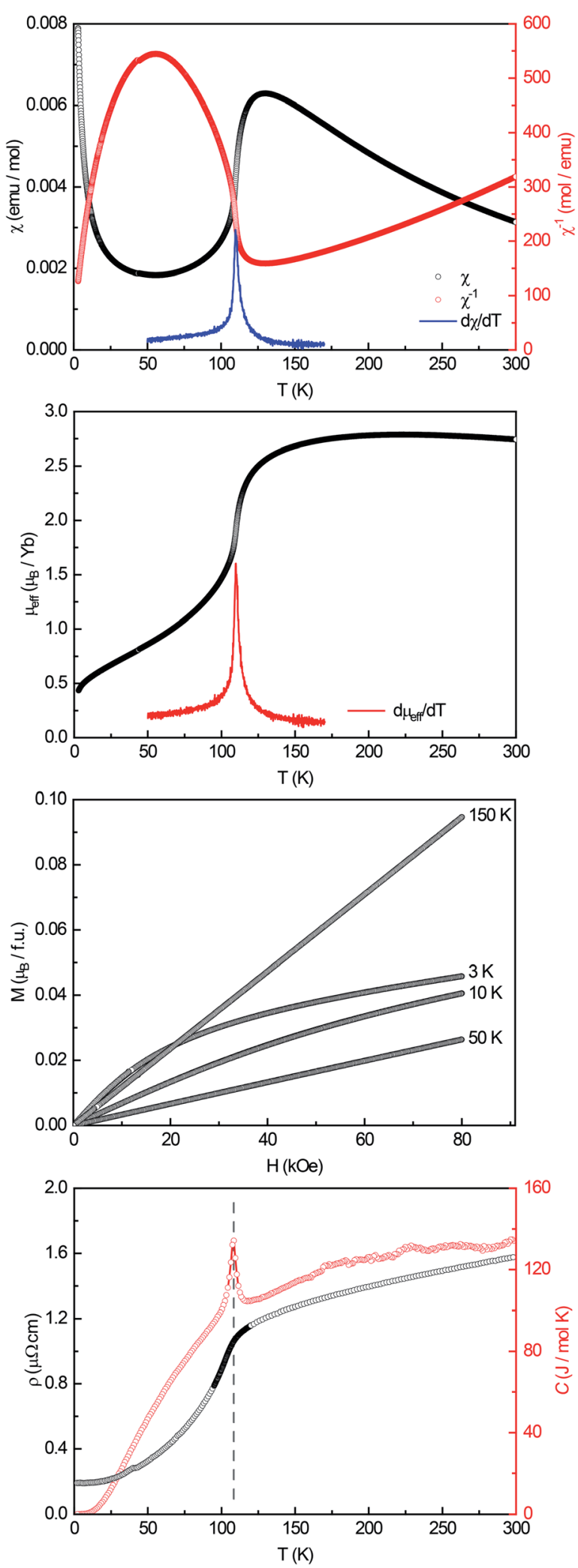

Fig. 4 Magnetic properties of $\mathrm{YbPd}_{2} \mathrm{Al}_{3}$. Top: temperature dependence of the magnetic susceptibility ( $\chi$ and $\chi^{-1}$ data) measured in ZFC mode at $10 \mathrm{kOe} ; \mathrm{d} \chi / \mathrm{d} T$ is shown in blue. Middle, top: temperature dependence of the effective magnetic moment; $d \mu_{\text {eff }} / d T$ is plotted in red. Middle, bottom: magnetization isotherms recorded at 3, 10, 50 and $150 \mathrm{~K}$. Bottom: temperature dependence of the electrical resistivity (black) and heat capacity (red). 
A similar behavior, also featuring a sharp rise of the magnetic susceptibility, was observed in the solid solution $\mathrm{Yb}_{x} \mathrm{In}_{1-x} \mathrm{Cu}_{2}$ with the strongest effect for $x=0.4 .^{29-31}$ The sharp rise was attributed to a spontaneous valence change from $\mathrm{Yb}^{2+}$ at low temperatures to $\mathrm{Yb}^{3+}$ at high temperatures with $T_{\text {anomaly }} \sim 50 \mathrm{~K}$. The observed magnetic behavior is furthermore significantly different compared to intermediate valence or valence fluctuating ytterbium compounds like $\mathrm{YbCu}_{2} \mathrm{Si}_{2},{ }^{52}$ $\mathrm{Yb}_{1-x} \mathrm{Sc}_{x} \mathrm{Al}_{2},{ }^{53} \mathrm{Yb}_{2} \mathrm{PdGe}_{6},{ }^{54}$ or $\mathrm{Yb}_{4} \mathrm{Pt}_{9} \mathrm{Ga}_{24}{ }^{14}$ which can be described by the interconfiguration fluctuation (ICF) model introduced by Sales and Wohlleben. ${ }^{52}$ The explanation of the susceptibility data via a valence phase transition is also in line with the observed structural effects (vide supra), since $\mathrm{Yb}^{2+}$ is significantly larger than $\mathrm{Yb}^{3+}\left(113\right.$ vs. $\left.86 \mathrm{pm}^{2}\right)$. An only partial $\mathrm{Yb}^{3+}$ character above $T_{\text {anomaly }}$ can be derived from the calculated magnetic moment of $\mu_{\text {eff }}=2.72(1) \mu_{\mathrm{B}}$ at $300 \mathrm{~K}$ measured at 10 kOe, which is significantly lower compared to the calculated moment of $\mu_{\text {calc }}=4.536 \mu_{\mathrm{B}}$ of a free $\mathrm{Yb}^{3+}$ ion. When looking back at the crystal structure, the two $\mathrm{Yb}$ sites have different site multiplicities (Yb1 on 2d, Yb2 on 1a). Therefore, a charge separation into $\mathrm{Yb}^{2+}$ and $\mathrm{Yb}^{3+}$ is possible. When calculating the net magnetic moment with the paramagnetic $\mathrm{Yb}^{3+}$ solely on the $2 \mathrm{~d}$ site an effective moment of $\mu_{\text {eff,calc }}=3.70 \mu_{\mathrm{B}}$ is obtained, while $\mathrm{Yb}^{3+}$ solely on the $1 \mathrm{a}$ site results in $\mu_{\text {eff,calc }}=2.62 \mu_{\mathrm{B}}$. The latter matches the observed effective moment quite well. This assumption is additionally underlined by the fact that the Yb1$\mathrm{Pd}$ and $\mathrm{Yb} 1-\mathrm{Al}$ distances enlarge upon the valence change from $\mathrm{Yb}^{3+} \rightarrow \mathrm{Yb}^{2+}$ as seen from the temperature dependent single crystal X-ray diffraction experiments. In order to check for a structural segregation of $\mathrm{Yb}^{2+}$ and $\mathrm{Yb}^{3+}$, members of the solid solution $\mathrm{Yb}_{1-x} \mathrm{Ca}_{x} \mathrm{Pd}_{2} \mathrm{Al}_{3}$ with $x=0.33$ and 0.67 have been synthesized. The results of these investigations will be discussed below.

In addition to the dc-magnetization experiments, heat capacity and electrical resistivity measurements have been performed. The heat capacity (Fig. 4, bottom, red) clearly shows a sharp and intense $\lambda$-shaped anomaly at $T_{\text {anomaly }}=108.4(1) \mathrm{K}$, in line with the other observed temperatures. Moreover, field dependent heat capacity measurements were conducted with applied magnetic fields of $H=0,10,50$ and 90 kOe (Fig. S2 $\dagger$ ) within a temperature range of $\pm 20 \mathrm{~K}$ around the anomaly. The observed temperature shifts are negligible, since all peak temperature are the same within three standard deviations. The change in the integrated areas can be explained by the stronger magnetic fields. Field dependent susceptibility measurements also indicate no temperature dependence of the anomaly (Fig. S3†). As both, the heat capacity and the susceptibility measurements show no significant temperature dependent shifts, no magnetic ordering takes place at the anomaly, in line with the $M(H)$ investigations. Additional ac-magnetic susceptibility measurements conducted on $\mathrm{YbPd}_{2} \mathrm{Al}_{3}$ revealed no frequency dependency of the zero-field as well as field dependent in-phase $\chi^{\prime}(\omega, T)$ and out-of-phase $\chi^{\prime \prime}(\omega, T)$ susceptibilities, therefore excluding dynamic processes or spin-glass behavior ${ }^{55}$ (Fig. S4 $\dagger$ ). In the resistivity measurements (Fig. 4, bottom, black) a nearly linear decrease is visible from 300 to $150 \mathrm{~K}$ before again an abrupt decrease is observed, coinciding with the anomaly visible in the heat capacity. This decrease can be explained by the localization of an electron into the open-shell $4 \mathrm{f}^{\mathbf{1 3}}$ configuration of $\mathrm{Yb}^{3+}$ to form the close-shell $\mathrm{Yb}^{2+}\left(4 \mathrm{f}^{14}\right)$ ion. The present behavior is comparable to the Kondo/impurity scattering observed for trivalent intermetallic cerium compounds $\left(4 \mathrm{f}^{1}\right)$, e.g. $\mathrm{Ce}_{3} \mathrm{Al}^{56}$ or $\mathrm{Ce}_{3} \mathrm{Al}_{11},{ }^{57}$ in which the resistivity drops significantly below the Kondo temperature. Trivalent $\mathrm{Yb}$ compounds act as 'hole' equivalents to the cerium compounds.

As mentioned before, the calculated magnetic moment of $\mathrm{YbPd}_{2} \mathrm{Al}_{3}$ is nearly in line with one $\mathrm{Yb}^{3+}$ and two $\mathrm{Yb}^{2+}$ ions per unit cell. Therefore, the divalent $\mathrm{Yb}^{2+}$ ions were replaced by the also diamagnetic $\mathrm{Ca}^{2+}$ ions, which are similar in size $\left(\mathrm{Ca}^{2+}: 106 \mathrm{pm}\right.$; $\mathrm{Yb}^{2+}: 113 \mathrm{pm}^{2}$ ) leading to an ideal formula of $\mathrm{Yb}_{0.33} \mathrm{Ca}_{0.67} \mathrm{Pd}_{2} \mathrm{Al}_{3}$. Additionally, also $\mathrm{Yb}_{0.67} \mathrm{Ca}_{0.33} \mathrm{Pd}_{2} \mathrm{Al}_{3}$ and the diamagnetic $\mathrm{CaPd}_{2} \mathrm{Al}_{3}$ were synthesized. All compounds were structurally as well as magnetically characterized. They exhibit a linear trend in the unit cell volume, known as Vegard behavior as well as a linear trend in the hexagonal lattice parameters (Table 1). The magnetic behavior is plotted in Fig. S5. $\dagger$ In comparison with $\mathrm{YbPd}_{2} \mathrm{Al}_{3}$, the Ca-containing members of the solid solutions $\mathrm{Yb}_{0.33} \mathrm{Ca}_{0.67} \mathrm{Pd}_{2} \mathrm{Al}_{3}$ and $\mathrm{Yb}_{0.67} \mathrm{Ca}_{0.33} \mathrm{Pd}_{2} \mathrm{Al}_{3}$ also exhibit a paramagnetic behavior, in line with $\mathrm{Yb}^{3+}$ contributions. From the magnitude of the magnetic susceptibility and the effective magnetic moment, it is evident that the amount of trivalent $\mathrm{Yb}$ atoms is decreasing (Fig. S6 $†$ ). As expected, $\mathrm{CaPd}_{2} \mathrm{Al}_{3}$ finally exhibits a temperature independent diamagnetic behavior $\left(\chi_{\text {dia }}=-1.28(1) \times 10^{-4} \mathrm{emu}\right.$ $\mathrm{mol}^{-1}$ at $\left.300 \mathrm{~K}\right)$. When looking at the data of $\mathrm{Yb}_{0.33} \mathrm{Ca}_{0.67} \mathrm{Pd}_{2} \mathrm{Al}_{3}$ and $\mathrm{Yb}_{0.67} \mathrm{Ca}_{0.33} \mathrm{Pd}_{2} \mathrm{Al}_{3}$, the "bump-like" feature is smeared and stretched over a larger temperature region; hence measurements up to $395 \mathrm{~K}$ were conducted. This behavior can be explained by the disorder in the solid solutions and the distribution of $\mathrm{Ca}$ and $\mathrm{Yb}$ on the two available crystallographic sites ( $1 a$ and $2 d)$, which has been proven by single-crystal structure investigations (Table $\mathrm{S} 2 \dagger$ ). However, due to the mixing of $\mathrm{Yb}$ and $\mathrm{Ca}$, no strict charge separation is present.

\subsection{X-ray photoelectron spectroscopy (XPS)}

When looking at intermetallic compounds with the general composition $\mathrm{RE}_{x} \mathrm{~T}_{y} \mathrm{X}_{z}$ (RE: rare-earth element, $\mathrm{T}$ : transition metal/group 6-12, X: element of group 13-15) the transition metal, especially when being a $5 \mathrm{~d}$ element, is the most electronegative element involved. We have shown for a number of gold (e.g. $\mathrm{Na}_{2} \mathrm{Au}_{3} \mathrm{Al},{ }^{58} \mathrm{AEAuX}(\mathrm{AE}=\mathrm{Ca}-\mathrm{Ba}, \mathrm{X}=\mathrm{Al}-\mathrm{In}),{ }^{59} \mathrm{AEAu}_{2} \mathrm{Al}_{2}(\mathrm{AE}$ $=\mathrm{Ca}, \mathrm{Sr})^{60}$ or $\mathrm{Ba}_{3} \mathrm{Au}_{5} \mathrm{Al}_{6}$ (ref. 60)) or platinum intermetallics (e.g. $\mathrm{Ba}_{3} \mathrm{Pt}_{4} \mathrm{Al}_{4}$ (ref. 61) and $\mathrm{REPt}_{2} \mathrm{Al}_{3}(\mathrm{RE}=\mathrm{Y}, \mathrm{Dy}-\mathrm{Tm})$ series ${ }^{62}$ ) that a significant electron transfer onto the $5 \mathrm{~d}$ metal takes places. For the presented compounds, electronegativities of $1.00(\mathrm{Ca}), 2.20$ (Pd) and 1.61 (Al), according to the Pauling scale, are found. ${ }^{2}$ For $\mathrm{Yb}$ no value is listed on this scale, however, for the neighboring elements values of $1.25(\mathrm{Tm})$ and $1.27(\mathrm{Lu})$ are reported, making Pd again the most electronegative element. ${ }^{2}$ Since the most electronegative elements acquire additional electron density, a shift towards lower binding energies can be observed in the respective XPS measurements. ${ }^{58-61}$

Fig. 5 (top) depicts the XPS spectra of the Pd 3d and Ca $2 \mathrm{p}$ lines of elemental Pd (black), $\mathrm{YbPd}_{2} \mathrm{Al}_{3}$ (red), $\mathrm{Yb}_{0.67} \mathrm{Ca}_{0.33} \mathrm{Pd}_{2} \mathrm{Al}_{3}$ 
(green), $\mathrm{Yb}_{0.33} \mathrm{Ca}_{0.67} \mathrm{Pd}_{2} \mathrm{Al}_{3}$ (blue), and $\mathrm{CaPd}_{2} \mathrm{Al}_{3}$ (orange). As can be seen from the plot and the data in Table 2, only minor shift of the $3 d_{5 / 2}$ and $3 d_{3 / 2}$ lines of the Pd reference and the investigated compounds can be observed. This is at the first glimpse slightly surprising, but can be explained in a straightforward manner. First, the electronegativity difference between $\mathrm{Pd}$ and $\mathrm{Al}$ is smaller compared to e.g. $\mathrm{Pt} / \mathrm{Al}$ or $\mathrm{Au} / \mathrm{Al}$. Also all investigated compounds exhibit more $\mathrm{Al}$ than $\mathrm{Pd}$ atoms (atomic ratio $3: 2$ ). Hence, electrons are needed for additional bonds in the $\left[\mathrm{Pd}_{2} \mathrm{Al}_{3}\right]^{\delta-}$ polyanion, reducing the electron density at the $\mathrm{Pd}$ atoms. In total, the electron density is close to metallic palladium with a small shift to lower binding energies, indicating a slightly negative charge on the Pd atoms. Additionally, a rather pronounced 'two-peak' structure is observed for $\mathrm{YbPd}_{2} \mathrm{Al}_{3}$. For the other investigated compounds, a tailing of the peaks towards higher binding energies is visible. This can be explained by so-called shake-up related effects. ${ }^{63,64}$ After photoionization, ions can be left in an excited energy state, which lies a few eV above the ground state. In these cases, the kinetic energy of the emitted photoelectron is reduced and can be seen as an additional peak at a higher binding energy compared to the main line. For metals, conduction electrons also can undergo shake-up events that follow the basic core electron photoemission. In these cases, instead of a discrete structure also only a tail on the higher binding energy side of the main can be evident. Similar effects, also causing satellite transitions are shake-down and shake-off events. For $\mathrm{Yb}_{0.67} \mathrm{Ca}_{0.33} \mathrm{Pd}_{2} \mathrm{Al}_{3}$, $\mathrm{Yb}_{0.33} \mathrm{Ca}_{0.67} \mathrm{Pd}_{2} \mathrm{Al}_{3}$ and $\mathrm{CaPd}_{2} \mathrm{Al}_{3}$, additionally the $\mathrm{Ca} 2 \mathrm{p}$ lines are observed in this region. These are in line with typical inorganic calcium compounds, e.g. $\mathrm{CaO},{ }^{65} \mathrm{CaCO}_{3},{ }^{66}$ or $\mathrm{CaMoO}_{4},{ }^{67}$ proving the electron transfer from the alkaline-earth atoms and the formal divalent oxidation state for calcium.

Fig. 5 (middle) depicts the XPS spectra of the $\mathrm{Yb} 4 \mathrm{~d}$ lines of $\mathrm{YbPd}_{2} \mathrm{Al}_{3}$ (black), $\mathrm{Yb}_{0.67} \mathrm{Ca}_{0.33} \mathrm{Pd}_{2} \mathrm{Al}_{3}$ (red) and $\mathrm{Yb}_{0.33} \mathrm{Ca}_{0.67} \mathrm{Pd}_{2} \mathrm{Al}_{3}$ (blue). The spectrum consists of five peaks that are easy visible (labeled a to e), which are caused by Coulomb and exchange interactions of the $\mathrm{Yb}^{3+}\left(4 \mathrm{f}^{13}\right)$ open shell ions. According to the literature, ${ }^{68,69}$ the peak a is attributed to ${ }^{3} \mathrm{H}_{6}$ and ${ }^{1} \mathrm{G}_{4}$ terms, the small peak c corresponds to the ${ }^{3} \mathrm{G}_{6}$ and ${ }^{1} \mathrm{~F}_{3}$ terms, while finally the broad peaks $d$ and e can be assigned to the ${ }^{3} \mathrm{G}_{4},{ }^{3} \mathrm{D}_{3}$ and ${ }^{3} \mathrm{P}_{2}$ as well as the ${ }^{1} \mathrm{H}_{5}$ terms, respectively. Peak b originates from the ${ }^{1} \mathrm{D}_{2}$ and ${ }^{3} \mathrm{H}_{5}$ terms, which overlaps the $4 \mathrm{~d}_{3 / 2}$ peak $\left(\mathrm{b}^{\prime}\right)$ of the divalent $\mathrm{Yb}$ atoms. These $\mathrm{Yb}^{2+}$ ions show a rather simple spectrum due to the completely filled $4 \mathrm{f}$ states. Hence, the exchange interaction between a core hole and the $4 \mathrm{f}$ electrons is negligible. The spectrum consists of a doublet of the $4 \mathrm{~d}_{5 / 2}\left(\mathrm{a}^{\prime}\right)$ and $4 \mathrm{~d}_{3 / 2}\left(\mathrm{~b}^{\prime}\right)$ peaks with a relative intensity ratio of $3: 2$, which has been fixed during fitting. The observed fit of the spectrum of $\mathrm{YbPd}_{2} \mathrm{Al}_{3}$ is depicted in Fig. 5 (bottom), the fits of the spectra of $\mathrm{Yb}_{0.67} \mathrm{Ca}_{0.33} \mathrm{Pd}_{2} \mathrm{Al}_{3}$ and $\mathrm{Yb}_{0.33} \mathrm{Ca}_{0.67} \mathrm{Pd}_{2} \mathrm{Al}_{3}$ are shown in the ESI $\dagger$ in Fig. $\mathrm{S} 7$ and S8. $\uparrow$ Since no cleaving or $\mathrm{Ar}^{+}$sputtering of the specimen was possible, surface oxidation due to sample handling in air or oxidation under X-ray radiation $\left(\mathrm{Yb}^{2+} \stackrel{\lambda}{\rightarrow} \mathrm{Yb}^{3+}\right)$ occurred. Similar X-ray induced oxidation processes have been observed for e.g. $\mathrm{EuCl}_{2},{ }^{70}$ where besides $\mathrm{Eu}^{2+}$ also significant amounts of $\mathrm{Eu}^{3+}$ are visible in the XPS investigations. Subsequently, the relative $\mathrm{Yb}^{3+}$ / $\mathrm{Yb}^{2+}$ ratio is significantly biased and cannot be used for the

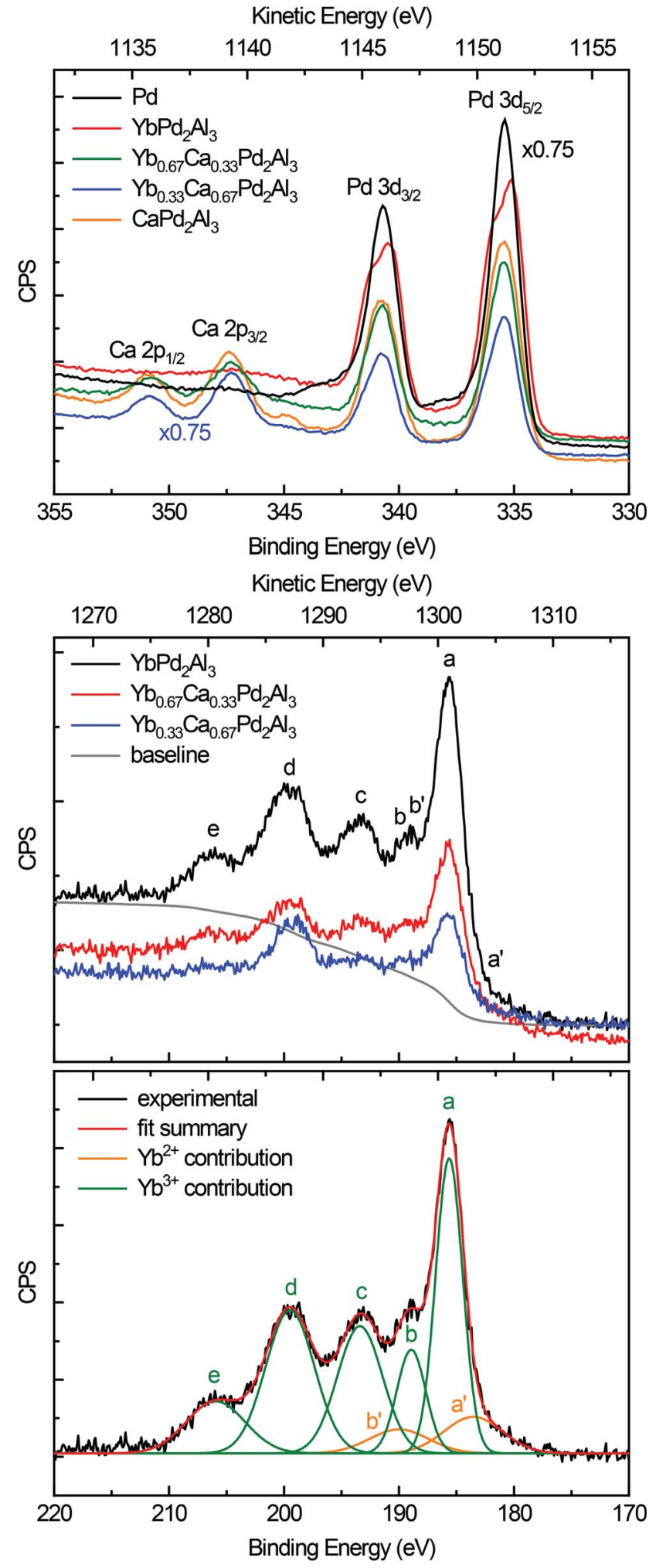

Fig. 5 (Top) $X$-ray photoemission spectra of the $\mathrm{Pd} 3 \mathrm{~d}$ and $\mathrm{Ca} 2 \mathrm{p}$ lines of elemental $\mathrm{Pd}$ (black), $\mathrm{YbPd}_{2} \mathrm{Al}_{3}$ (red), $\mathrm{Yb}_{0.67} \mathrm{Ca}_{0.33} \mathrm{Pd}_{2} \mathrm{Al}_{3}$ (green), $\mathrm{Yb}_{0.33} \mathrm{Ca}_{0.67} \mathrm{Pd}_{2} \mathrm{Al}_{3}$ (blue), and $\mathrm{CaPd}_{2} \mathrm{Al}_{3}$ (orange). (Middle) $\mathrm{X}$ ray photoemission spectra of the $\mathrm{Yb} 4 \mathrm{~d}$ lines of $\mathrm{YbPd}_{2} \mathrm{Al}_{3}$ (black), $\mathrm{Yb}_{0.67} \mathrm{Ca}_{0.33} \mathrm{Pd}_{2} \mathrm{Al}_{3}$ (red), and $\mathrm{Yb}_{0.33} \mathrm{Ca}_{0.67} \mathrm{Pd}_{2} \mathrm{Al}_{3}$ (blue). The background of $\mathrm{YbPd}_{2} \mathrm{Al}_{3}$ is depicted as solid grey line. (bottom) Fit of the $X$ ray photoemission spectra of the $\mathrm{Yb} 4 \mathrm{~d}$ lines of $\mathrm{YbPd}_{2} \mathrm{Al}_{3}$. The sum is depicted in red. (CPS = counts per second, linear scale). 
determination of the amount of $\mathrm{Yb}^{2+}$ present in the sample. However, the presence of both lines still proves the presence of both, di- and trivalent $\mathrm{Yb}$ atoms. A better quantification might be achievable using Hard X-ray Photoelectron Spectroscopy (HAXPES) investigations which can monitor the $\mathrm{Yb} 3 \mathrm{~d}_{3 / 2}$ and $3 \mathrm{~d}_{5 / 2}$ or XANES measurements.

\section{Conclusion}

$\mathrm{YbPd}_{2} \mathrm{Al}_{3}$ and its solid solution $\mathrm{Yb}_{1-x} \mathrm{Ca}_{x} \mathrm{Pd}_{2} \mathrm{Al}_{3}(x=0.33,0.67$, 1) have been synthesized from the elements using sealed tantalum ampoules. The compounds crystallize in the hexagonal $\mathrm{YNi}_{2} \mathrm{Al}_{3}$ type structure $(P 6 / \mathrm{mmm})$ with lattice parameters of $a=930-936$ and $c=420-424 \mathrm{pm}$. During dc magnetic susceptibility measurements, an anomaly at $T_{\text {anomaly }} \sim 110 \mathrm{~K}$ was observed. Antiferromagnetic ordering was discarded due to the recorded magnetization isotherms, the observed expansion of the unit cell below $T_{\text {anomaly }}$ and the absence of a significant shift in field dependent heat capacity and dc susceptibility measurements. The observed feature is also visible in measurements of the electrical resistivity and the heat capacity, in contrast, no dynamic features were observed in ac magnetization experiments. Therefore, this feature can only be attributed to a temperature induced ytterbium valence change. While above $110 \mathrm{~K}$ a mixed-valent $\mathrm{Yb}$ state (as seen from the effective magnetic moment) is present, an intrinsic one electron reduction upon formation of a nearly diamagnetic compound at low temperatures takes place. The temperature induced valence change is not only characterized by the drastically expansion of the $c$ axis, observed in temperature dependent powder and single-crystal X-ray measurements, but also by a significant distortion of the Yb1 polyhedra. XPS investigation proved the presence of $\mathrm{Yb}^{2+}$ and $\mathrm{Yb}^{3+}$, however, overestimating the amounts of trivalent $\mathrm{Yb}$ due to surface oxidation of the specimen. A possible explanation for this valence change is the lower overall energy of the purely divalent system at low temperatures, since the open shell $4 \mathrm{f}^{13}$ system of $\mathrm{Yb}^{3+}$ transitions into a fully closed shell $\mathrm{Yb}^{2+}\left(4 \mathrm{f}^{14}\right)$ system.

\section{Conflicts of interest}

There are no conflicts to declare.

\section{Acknowledgements}

We thank Dipl.-Chem. Simon Gausebeck for the help with the sample preparation, Dr R.-D. Hoffmann, Dipl.-Ing. U. Ch. Rodelwald and Dipl.-Ing. J. Kösters for the collection of the single-crystal diffractometer data.

\section{References}

1 A. Szytuła and J. Leciejewicz, Handbook of Crystal Structures and Magnetic Properties of Rare Earth Intermetallics, CRC Press, Boca Raton, 1994.

2 J. Emsley, The Elements, Clarendon Press, Oxford University Press, Oxford, New York, 1998.
3 S. Cotton, Lanthanides \& Actinides, Macmillan Education LTD, Houndsmillo, Basingstoke, Hampsire, London, 1991.

4 H. Bärnighausen and G. Brauer, Acta Crystallogr., 1962, 15, 1059.

5 R. Rau, Acta Crystallogr., 1966, 20, 716-723.

6 F. F. Y. Wang, Phys. Status Solidi B, 1966, 14, 189-192.

7 M. Glätzle, O. Janka, V. Svitlyk, D. Chernyshov, M. Bartsch, H. Zacharias, R. Pöttgen and H. Huppertz, Chem.-Eur. J., 2018, 24, 15236-15245.

8 Z. Haque, G. S. Thakur, R. Parthasarathy, B. Gerke, T. Block, L. Heletta, R. Pöttgen, A. G. Joshi, G. K. Selvan, S. Arumugam, L. C. Gupta and A. K. Ganguli, Inorg. Chem., 2017, 56, 31823189.

9 M. B. Gamża, R. Gumeniuk, U. Burkhardt, W. Schnelle, H. Rosner, A. Leithe-Jasper and A. Ślebarski, Phys. Rev. B, 2017, 95, 165142.

10 F. L. Carter, J. Solid State Chem., 1972, 5, 300-313.

11 N. Lossau, H. Kierspel, J. Langen, W. Schlabitz, D. Wohlleben, A. Mewis and C. Sauer, Z. Phys. B: Condens. Matter, 1989, 74, 227-232.

12 K. H. J. Buschow and H. J. Vandall, Solid State Commun., 1970, 8, 363-365.

13 K. H. Mader and W. M. Swift, J. Phys. Chem. Solids, 1968, 29, 1759-1764.

14 O. Sichevych, Y. Prots, Y. Utsumi, L. Akselrud, M. Schmidt, U. Burkhardt, M. Coduri, W. Schnelle, M. Bobnar, Y.-T. Wang, Y.-H. Wu, K.-D. Tsuei, L. H. Tjeng and Y. Grin, Inorg. Chem., 2017, 56, 9343-9352.

15 U. B. Paramanik, U. Anupam, U. Burkhardt, R. Prasad, C. Geibel and Z. Hossain, J. Alloys Compd., 2013, 580, 435-441.

16 O. Niehaus, U. C. Rodewald, P. M. Abdala, R. S. Touzani, B. P. T. Fokwa and O. Janka, Inorg. Chem., 2014, 53, 24712480.

17 B. Batlogg, E. Kaldis, A. Schlegel, G. von Schulthess and P. Wachter, Solid State Commun., 1976, 19, 673-676.

18 B. Batlogg, E. Kaldis and P. Wachter, J. Magn. Magn. Mater., 1976, 3, 96-98.

19 D. C. Koskenmaki and K. A. Gschneidner Jr, Handbook on the Physics and Chemistry of Rare Earths, 1978, vol. 1, p. 337.

20 M. Wakeshima, Y. Izumiyama, Y. Doi and Y. Hinatsu, Solid State Commun., 2001, 120, 273-278.

21 A. Jayaraman, V. Narayanamurti, E. Bucher and R. G. Maines, Phys. Rev. Lett., 1970, 25, 1430-1433.

22 E. Kaldis and P. Wachter, Solid State Commun., 1972, 11, 907-912.

23 M. Akihiro, M. Shigeki, U. Masafumi, W. Hirofumi, M. Kazuyuki, U. Yoshiya, M. Masaichiro, K. Naomi, N. Kiyofumi, H. Naohisa, O. Yasuo and I. Naoki, J. Phys.: Condens. Matter, 2018, 30, 105603.

24 A. P. Menushenkov, A. A. Yaroslavtsev, A. Y. Geondzhian, R. V. Chernikov, L. Nataf, X. Tan and M. Shatruk, J. Supercond. Novel Magn., 2017, 30, 75-78.

25 R. S. Kumar, A. Svane, G. Vaitheeswaran, V. Kanchana, E. D. Bauer, M. Hu, M. F. Nicol and A. L. Cornelius, Phys. Rev. B: Condens. Matter Mater. Phys., 2008, 78, 075117. 
26 E. V. Sampathkumaran, L. C. Gupta, R. Vijayaraghavan, K. V. Gopalakrishnan, R. G. Pillay and H. G. Devare, J. Phys. C: Solid State Phys., 1981, 14, L237.

27 M. Radzieowski, F. Stegemann, T. Block, J. Stahl, D. Johrendt and O. Janka, J. Am. Chem. Soc., 2018, 140, 8950-8957.

28 D. T. Adroja, B. D. Rainford, J. M. de Teresa, A. del Moral, M. R. Ibarra and K. S. Knight, Phys. Rev. B: Condens. Matter Mater. Phys., 1995, 52, 12790-12797.

29 I. Felner and I. Nowik, Phys. Rev. B: Condens. Matter Mater. Phys., 1986, 33, 617-619.

30 I. Felner, I. Nowik, D. Vaknin, U. Potzel, J. Moser, G. M. Kalvius, G. Wortmann, G. Schmiester, G. Hilscher, E. Gratz, C. Schmitzer, N. Pillmayr, K. G. Prasad, H. de Waard and H. Pinto, Phys. Rev. B: Condens. Matter Mater. Phys., 1987, 35, 6956-6963.

31 H. Müller, E. Bauer, E. Gratz, K. Yoshimura, T. Nitta and M. Mekata, J. Magn. Magn. Mater., 1988, 76, 159-160.

32 O. S. Zarechnyuk and R. M. Rykhal', Visnyk Lvivskoho Derzhavnoho Universytetu Serija Khimichna, 1981, 23, 45-47.

33 R. Pöttgen, T. Gulden and A. Simon, GIT Labor-Fachz., 1999, 43, 133-136.

34 D. Kußmann, R.-D. Hoffmann and R. Pöttgen, Z. Anorg. Allg. Chem., 1998, 624, 1727-1735.

35 K. Yvon, W. Jeitschko and E. Parthé, J. Appl. Crystallogr., 1977, 10, 73-74.

36 Dectris, Pilatus 100K-S Detector System, Technical Specification and Operating Procedure (version 1.7), Baden, 2011.

37 L. J. van der Pauw, Philips research reports, 1958, 13, 1-9.

38 P. Villars and K. Cenzual, Pearson's Crystal Data: Crystal Structure Database for Inorganic Compounds (on DVD), ASM International $\AA$, Materials Park, Ohio (USA), release 2018/ 2019.

39 L. Palatinus and G. Chapuis, J. Appl. Crystallogr., 2007, 40, 786-790.

40 V. Petříček, M. Dušek and L. Palatinus, Jana2006, The crystallographic computing system, Institute of Physics, Praha, Czech Republic, 2006.

41 V. Petříček, M. Dušek and L. Palatinus, Z. Kristallogr., 2014, 229, 345-352.

42 T. Roisnel and R. Rodríguez-Carvajal, Materials Science Forum, Proceedings of the Seventh European Powder Diffraction Conference (EPDIC 7), 2000, pp. 118-123.

43 J. Rodríguez-Carvajal, Phys. B, 1993, 192, 55-69.

44 F. Eustermann, R.-D. Hoffmann and O. Janka, Z. Kristallogr., 2017, 232, 573-581.

45 H. Pfisterer and K. Schubert, Naturwissenschaften, 1950, 37, 112-113.

46 K. Schubert, H. Breimer, W. Burkhardt, E. Günzel, R. Haufler, H. L. Lukas, H. Vetter, J. Wegst and M. Wilkens, Naturwissenschaften, 1957, 44, 229-230.

47 G. Cordier, T. Friedrich, R. Henseleit, A. Grauel, U. Tegel, C. Schank and C. Geibel, J. Alloys Compd., 1993, 201, 197201.
48 G. Cordier and R. Henseleit, Z. Kristallogr., 1993, 203, 144145.

49 S. Surjeet and S. K. Dhar, J. Phys.: Condens. Matter, 2002, 14, 11795.

50 A. W. Hull, Phys. Rev., 1917, 10, 661-696.

51 R. M. Moon, W. C. Koehler, H. R. Child and L. J. Raubenheimer, Phys. Rev., 1968, 176, 722-731.

52 B. C. Sales and D. K. Wohlleben, Phys. Rev. Lett., 1975, 35, 1240-1244.

53 G. J. Lehr, D. T. Morelli, H. Jin and J. P. Heremans, J. Appl. Phys., 2013, 114, 223712.

54 D. Kaczorowski, A. V. Gribanov, P. Rogl and S. F. Dunaev, J. Alloys Compd., 2016, 685, 957-961.

55 J. A. Mydosh, J. Magn. Magn. Mater., 1996, 157-158, 606-610. 56 M. Sera, T. Satoh and T. Kasuya, J. Magn. Magn. Mater., 1987, 63-64, 82-84.

57 H. J. Van Daal and K. H. J. Buschow, Phys. Lett. A, 1970, 31, 103-104.

58 F. Stegemann, C. Benndorf, Y. Zhang, M. Bartsch, H. Zacharias, B. P. T. Fokwa, H. Eckert and O. Janka, Inorg. Chem., 2017, 56, 1919-1931.

59 C. Benndorf, F. Stegemann, S. Seidel, L. Schubert, M. Bartsch, H. Zacharias, B. Mausolf, F. Haarmann, H. Eckert, R. Pöttgen and O. Janka, Chem.-Eur. J., 2017, 23, 4187-4196.

60 F. Stegemann, C. Benndorf, Y. Zhang, M. Bartsch, H. Zacharias, B. P. T. Fokwa, H. Eckert and O. Janka, Z. Anorg. Allg. Chem., 2017, 643, 1379-1390.

61 F. Stegemann, C. Benndorf, T. Bartsch, R. S. Touzani, M. Bartsch, H. Zacharias, B. P. T. Fokwa, H. Eckert and O. Janka, Inorg. Chem., 2015, 54, 10785-10793.

62 F. Eustermann, S. Gausebeck, C. Dosche, M. Haensch, G. Wittstock and O. Janka, Crystals, 2018, 8, 169.

63 D. Briggs, Surface analysis by Auger and X-ray photoelectron spectroscopy SurfaceSpectra, Manchester, 2003.

64 S. Hüfner, Photoelectron spectroscopy Springer, Berlin, 2010. 65 H. Van Doveren and J. A. T. H. Verhoeven, J. Electron Spectrosc. Relat. Phenom., 1980, 21, 265-273.

66 Q. Liu, J. S. Laskowski, Y. Li and D. Wang, Int. J. Miner. Process., 1994, 42, 251-266.

67 V. I. Nefedov, M. N. Firsov and I. S. Shaplygin, J. Electron Spectrosc. Relat. Phenom., 1982, 26, 65-78.

68 Y. Ohno, J. Electron Spectrosc. Relat. Phenom., 2008, 165, 1-4. 69 I. Chorkendorff, J. Onsgaard, J. Schmidt-May and R. Nyholm, Surf. Sci., 1985, 160, 587-598.

70 D. Kim, Y.-H. Jin, K.-W. Jeon, S. Kim, S.-J. Kim, O. H. Han, D.-K. Seo and J.-C. Park, RSC Adv., 2015, 5, 74790-74801.

71 S. B. M. Hagström, P. O. Hedén and H. Löfgren, Solid State Commun., 1970, 8, 1245-1248.

72 F. U. Hillebrecht, J. C. Fuggle, P. A. Bennett, Z. Zołnierek and C. Freiburg, Phys. Rev. B: Condens. Matter Mater. Phys., 1983, 27, 2179-2193.

73 K. Kishi, Y. Motoyoshi and S. Ikeda, Surf. Sci., 1981, 105, 313324. 